Mosul Journal of Nursing, Vol. 7, No. 1, 2019 ( $44-52$ )

Mosul Journal of Nursing

www.mjn.mosuljournals.com

\title{
Assessment of Health Problems for Patients with Goiter in Baghdad Teaching Hospital
}

Article information

Article history:

Received May 28, 2018

Accepted February 26, 2019

Available online May 30, 2019

\author{
DOI: 10.33899/mjn.2019.162874 @2020, College of Nursing, University of Mosul \\ Creative Commons Attribution 4.0 International License \\ https://mjn.mosuljournals.com/article 162874.html \\ Hussein Hadi Atiyah ${ }^{1}$
}

\section{Abstract}

Background. Iodine-deficiency disorders are a major public health problem all over the world. Goiter is the most visible manifestation of iodine-deficiency disorder. This study assessed of health problems for patients with goiter in Baghdad teaching hospital.

Objective:- The study aims to assess health problems for patients with goiter and to find out the relationship between health problems with demographic characteristics.

Methodology: - A descriptive study was carried out in Baghdad teaching hospital for the period from $1 \backslash 2 \backslash 2017$ to 2\4\2018. A purposive (non probability) sample of (60) patients. Questionnaire was constructed for the purpose of the study. Data were collected through the application of the questionnaire and interview technique. Data were analyzed through descriptive statistical approach (frequency and percentage) and inferential statistical approach (Pearson correlation and mean of score) by using of SPSS 16.0

Results: The study results indicated that the age group was between (20-30) year and most of them less than 30 years old.Most of the study samples(71.7\%) were female, and (60\%) were married and (78.3\%) living in rural area and (36.7\%) were secondary school graduate and $(60 \%)$ were employed, with(50\%) have barely sufficient monthly income. Most of the study sample (40\%) were suffering from the disease for period (1-2) years.

Conclusions:- The findings of the study samples indicated that moderate severity of physiological problems and high severity in some items such us (Palpitation, Dyspnea, Weakness, and Hand sweat) and also moderate severity in psychosocial problems and high severity in some items such us (Decrease self esteem, Change in body image, Change in eating patterns, and Nervousness). There is strong positive relationship between health problems with (physiological problems and psychosocial problems).

Recommendation:-The study recommended that educational programs should be constructed or designed for patients toward health care awareness for patients with goiter. The nurse must periodically assess the health of the patient with goiter. The patient is reminded to avoid tea, coffee, cola, and other stimulants.

Keyword: Health problems for Goiter

\footnotetext{
${ }^{1}$ PhD. Adult Nursing, Assist. Prof. College of Nursing, University of Baghdad.
} 


\section{Mosul Journal of Nursing, Vol. 7, No. 1, 2019 ( 44-52 )}

Introduction

Goiter is an umbrella medical term that can be used to describe any swelling or enlargement of the thyroid gland. Thyroid gland's metabolic function is essential for normal functioning human body. The aforementioned metabolic function of Thyroid gland is controlled by its endocrine hormones Triiodothyronine (T3) and Thyroxine (T4) ${ }^{(1)}$. India as an example of an Asian country that is facing an increasing incidence of epidemic goiter as a major public health problem ${ }^{(4)}$. Whereas, 200 million individuals inhabit at goiter endemic regions. 71 million of them are medically diagnosed with deficiency disorders ${ }^{(6,7)}$. Goiters does not discriminate among people, it affects individuals across the life-span, both genders, and different epidemic goiter by supporting the highly vulnerable population with iodine compounds such as iodized salt. However, excessive $\mathrm{NaCl}$ is an important risk factors of blood pressurerelated health problems ${ }^{(2)}$.

Goiter impact maybe reflected in a systematic-fusion, examples of the most common health problems which are associated with goiter are however, not limited to: breathing difficulties, dysphagia, voice hoarseness, \& Methodology

A descriptive analytic study was carried out throughout the present study to assessed health problems (physiological and psychosocial problems) for patients who attended the inpatient in Baghdad teaching hospital in Baghdad city. The study was carried out during the period extended from the $1^{\text {st }}$ February 2017 to $2^{\text {nd }}$ April 2018.

In order to obtain valid and comprehensive data, the study was conducted inpatient. The following was included Baghdad teaching hospital.

In order to obtain accurate data and representative sample, a non probability (purposive) sample was selected. The sample consisted of (60) patients. These patients were attending inpatients in Baghdad teaching hospital in Baghdad city.

A questionnaire- interview format was designed and developed by the researcher for the purpose of the study; such development was socio-demographic characteristics of people ${ }^{(5)}$. Goiter is not an exclusive health problem for developing countries, the literature has shown that developed nations such as, United Kingdom, France, Italy, Ireland, and United States of America have been impacted by insufficient iodine intake, predominantly in pregnant women, which may jeopardize pregnancy outcome ${ }^{(17)}$. Another example of the Iodine deficiency is represented by Turkey, a Middleeastern developing county, at which three quarters of the people have this problem as a direct result of low iodine diet and family history of the aforementioned health problem ${ }^{(16)}$. Therefore, the World Health Organization(WHO), tried to address the

cough. Both hypo and hyperthyroidism related health problems such as nervousness, weight loss, fatigue, palpitations may be seen when examining patient's history ${ }^{(18)}$. Assessing such life-threatening health problems can be of a great clinical value as it furnishes the way for nurses to provide a tailored care plan aiming basically at addressing these problems $(20,21)$. Which justify conduction of the current study.

employed through the available literatures, clinical background and interview with patients who has goiter.

All the items were measured on scale of (3) indicates that the problems were persistent as (always) and (2) Indicates presence of the problems as (sometimes) and (1) indicates the absence of the problems as (never). Rating scale was used to rate the frequency and extension of the problems.

The questionnaire consist 3 parts: part one which deals with demographic characteristics. It consisted of (8) items included (age, gender, marital status, residential area, level of education, occupation, monthly income, and duration of disease). While the second part deals with physiological problems aspects they consist of (16) items. The third part deals with psychosocial problems they consist of (11) items.

The content validity of the instrument was established through a panel of (10) experts. The years of experience with mean of (19.5) years, 


\section{Mosul Journal of Nursing, Vol. 7, No. 1, 2019 ( 44-52 )}

and $(\mathrm{Sd}=7.43)$. They were asked to determine the content validity and investigate the clarify adequacy of the study questionnaire.

Test-Retest reliability was employed through computation of Pearson Correlation Coefficient ( $\mathrm{r}=0.84)$.

The data were collected by using the questionnaire structured format through interview technique. Each patient was interviewed personally by the researcher. Each interview took approximately from (15-25) minutes. Data were collected between 8.30 am to $1.30 \mathrm{pm}$. The assessment was conducted during the period of the $9^{\text {th }}$ June 2017 to $15^{\text {th }}$ February 2018.

Data were analyzed through descriptive statistical approach (frequency and percentage) and inferential statistical approach (Pearson correlation and mean of score) by using of SPSS 16.0

\section{Results}

Table (1) Distribution of demographic characteristics of (60) patients with goiter.

\begin{tabular}{|c|c|c|c|c|}
\hline No & Variables & \multirow[t]{2}{*}{ Frequency } & \multirow[t]{2}{*}{ percent } & \multirow[t]{2}{*}{ Cumulative percent } \\
\hline 1 & Age ( years ) & & & \\
\hline 1.1 & $(10-20)$ & 8 & 13.3 & 13.3 \\
\hline 1.2 & $(20-30)$ & 23 & 38.3 & 51.7 \\
\hline 1.3 & $(30-40)$ & 13 & 21.7 & 73.3 \\
\hline 1.4 & $(40-50)$ & 10 & 16.7 & 90.0 \\
\hline \multirow[t]{2}{*}{1.5} & $(50-60)$ & 6 & 10.0 & 100.0 \\
\hline & Total & 60 & 100.0 & \\
\hline 2 & Gender & Frequency & percent & Cumulative percent \\
\hline 2.1 & Male & 17 & 28.3 & 28.3 \\
\hline \multirow[t]{2}{*}{2.2} & Female & 43 & 71.7 & 100.0 \\
\hline & Total & 60 & 100.0 & \\
\hline 3 & Marital status & Frequency & percent & Cumulative percent \\
\hline 3-1 & Married & 36 & 60.0 & 60.0 \\
\hline \multirow[t]{2}{*}{$3-2$} & Single & 24 & 40.0 & 100.0 \\
\hline & Total & 60 & 100.0 & \\
\hline 4 & Residence & Frequency & percent & Cumulative percent \\
\hline 4-1 & Rural & 47 & 78.3 & 78.3 \\
\hline \multirow[t]{2}{*}{ 4-2 } & Urban & 13 & 21.7 & 100.0 \\
\hline & Total & 60 & 100.0 & \\
\hline 5 & Level of education & Frequency & percent & Cumulative percent \\
\hline $5-1$ & Read \& Write & 5 & 8.3 & 8.3 \\
\hline $5-2$ & Primary school graduate & 16 & 26.7 & 35.0 \\
\hline $5-3$ & Secondary school graduate & 22 & 36.7 & 71.7 \\
\hline \multirow[t]{2}{*}{$5-4$} & Institution and above & 17 & 28.3 & 100.0 \\
\hline & Total & 60 & 100.0 & \\
\hline 6 & Occupation & Frequency & percent & Cumulative percent \\
\hline 6-1 & Employed & 36 & 60.0 & 60.0 \\
\hline \multirow[t]{2}{*}{$6-2$} & Unemployed & 24 & 40.0 & 100.0 \\
\hline & Total & 60 & 100.0 & \\
\hline
\end{tabular}


Mosul Journal of Nursing, Vol. 7, No. 1, 2019 ( 44-52 )

\begin{tabular}{|c|l|c|c|c|}
\hline 7 & Monthly income & Frequency & percent & Cumulative percent \\
\hline $7-1$ & Sufficient & $\mathbf{1 8}$ & $\mathbf{3 0 . 0}$ & $\mathbf{3 0 . 0}$ \\
\hline $7-2$ & Barely Sufficient & $\mathbf{3 0}$ & $\mathbf{5 0 . 0}$ & $\mathbf{8 0 . 0}$ \\
\hline $7-3$ & Insufficient & 12 & $\mathbf{2 0 . 0}$ & $\mathbf{1 0 0 . 0}$ \\
\hline & Total & $\mathbf{6 0}$ & $\mathbf{1 0 0 . 0}$ & \\
\hline 8 & Duration of disease (years) & Frequency & percent & Cumulative percent \\
\hline $8-1$ & $(1-2)$ & 24 & $\mathbf{4 0 . 0}$ & $\mathbf{4 0 . 0}$ \\
\hline $8-2$ & $(3-4)$ & 17 & 28.3 & $\mathbf{6 8 . 3}$ \\
\hline $8-3$ & $(5-6)$ & 12 & $\mathbf{2 0 . 0}$ & $\mathbf{8 8 . 3}$ \\
\hline $8-4$ & $(6-8)$ & 7 & 11.7 & 100.0 \\
\hline & Total & 60 & 100.0 & \\
\hline
\end{tabular}

This table shows that the age group was (20-30) years and most of them less than 30 years old. Most of the study samples $(71.7 \%)$ were female. Most of them $(60 \%)$ were married and $(78.3 \%)$ living in rural area and $(36.7 \%)$ were secondary school graduate. The majority of the study samples $(60 \%)$ were employed and

Table (2) Mean of score for the items of the (physiological problems)

\begin{tabular}{|c|l|c|c|c|c|c|}
\hline No & \multicolumn{1}{|c|}{ Items } & Always & Some time & Never & M.S. & Severity \\
\hline 1 & Flushed, smooth skin & 13 & 30 & 17 & 1.93 & M \\
\hline 2 & Heat intolerance & 24 & 22 & 14 & 2.17 & M \\
\hline 3 & Tachycardia & 25 & 22 & 13 & 2.20 & M \\
\hline 4 & Diaphoresis & 15 & 12 & 33 & 1.70 & M \\
\hline 5 & Palpitation & 42 & 10 & 8 & 2.57 & H \\
\hline 6 & Dyspnea & 45 & 8 & 7 & 2.63 & H \\
\hline 7 & Weakness & 42 & 11 & 7 & 2.58 & H \\
\hline 8 & Increased hunger & 12 & 16 & 32 & 1.67 & M \\
\hline 9 & Tackypnea & 19 & 12 & 29 & 1.83 & M \\
\hline 10 & Hand tremors & 32 & 16 & 12 & 2.33 & M \\
\hline 11 & Tongue tremors & 28 & 16 & 16 & 2.20 & M \\
\hline 12 & Exophthalmoses & 2 & 10 & 48 & 1.23 & L \\
\hline 13 & Weight loss & 25 & 18 & 17 & 2.13 & M \\
\hline 14 & Diarrhea & 27 & 19 & 14 & 2.22 & M \\
\hline 15 & Hyperhydrosis & 11 & 6 & 43 & 1.47 & L \\
\hline 16 & Hand sweat & 44 & 12 & 4 & 2.67 & H \\
\hline & Total & 406 & 240 & 314 & 2.10 & M \\
\hline
\end{tabular}

This table shows that the mean of score are high on items $(5,6,7$, and 16) and low on items (12, and15). The mean of score are moderate on the remaining items.

Table (3) Mean of score for the items of (psychosocial problems).

\begin{tabular}{|c|l|c|c|c|c|c|}
\hline No & \multicolumn{1}{|c|}{ Items } & Always & Some time & Never & M.S. & Severity \\
\hline 1 & Decrease self esteem & 38 & 18 & 4 & 2.57 & H \\
\hline 2 & Change in body image & 39 & 17 & 4 & 2.58 & H \\
\hline
\end{tabular}


Mosul Journal of Nursing, Vol. 7, No. 1, 2019 ( 44-52 )

\begin{tabular}{|c|l|c|c|c|c|c|}
\hline 3 & Disruption employment & 28 & 20 & 12 & 2.27 & M \\
\hline 4 & $\begin{array}{l}\text { Physical activity } \\
\text { restriction }\end{array}$ & 29 & 19 & 12 & 2.28 & M \\
\hline 5 & $\begin{array}{l}\text { Adjustment to change in } \\
\text { occupation }\end{array}$ & 10 & 23 & 27 & 1.72 & M \\
\hline 6 & $\begin{array}{l}\text { Social withdrawal and } \\
\text { isolation }\end{array}$ & 18 & 25 & 17 & 2.02 & M \\
\hline 7 & Change in eating patterns & 42 & 13 & 5 & 2.62 & H \\
\hline 8 & $\begin{array}{l}\text { Change in role } \\
\text { performance }\end{array}$ & 15 & 18 & 27 & 1.80 & M \\
\hline 9 & Change in sexual function & 3 & 22 & 35 & 1.47 & L \\
\hline 10 & Mood swings & 21 & 17 & 22 & 1.98 & M \\
\hline 11 & Nervousness & 44 & 12 & 4 & 2.67 & H \\
\hline & Total & 287 & 204 & 169 & 2.18 & M \\
\hline
\end{tabular}

This table show that the mean of score are high on items (1,2, 7, and 11) and low on item (9). The mean of score are moderate on the remaining items.

Table -4- correlation coefficient between (age, gender, residence, level of education, Occupation, Duration of disease, physiological, and psychosocial problems) with health problems.

\begin{tabular}{|c|c|c|c|c|c|c|c|c|}
\hline Correlation & age & $\begin{array}{l}\text { gende } \\
\mathbf{r}\end{array}$ & $\begin{array}{l}\text { residenc } \\
\text { e }\end{array}$ & $\begin{array}{l}\text { educatio } \\
\text { n }\end{array}$ & $\begin{array}{l}\text { occupatio } \\
\text { n }\end{array}$ & $\begin{array}{l}\text { duratio } \\
\text { n }\end{array}$ & $\begin{array}{l}\text { physiologic } \\
\text { al }\end{array}$ & $\begin{array}{l}\text { psychosocia } \\
\text { l }\end{array}$ \\
\hline Age & 1 & & & & & & & \\
\hline Gender & $\begin{array}{l}- \\
.369\end{array}$ & 1 & & & & & & \\
\hline Residence & .228 & -.208 & 1 & & & & & \\
\hline Education & $\begin{array}{l}- \\
.357\end{array}$ & $-.062-$ & $-.569^{* *}$ & 1 & & & & \\
\hline Occupation & $\begin{array}{l}- \\
.408\end{array}$ & $.287^{*}$ & .066 & $-.161-$ & 1 & & & \\
\hline Duration & .539 & $-660^{* * *}$ & $-.017-$ & .092 & $-.455^{* *}$ & 1 & & \\
\hline Physical & .126 & $-.087-$ & $-.010-$ & $-.009-$ & $-.179-$ & .149 & 1 & \\
\hline $\begin{array}{l}\text { Psychosocia } \\
\text { l }\end{array}$ & .067 & $-.102-$ & $-.112-$ & .132 & $-.149-$ & $.275^{*}$ & .052 & 1 \\
\hline $\begin{array}{l}\text { Health } \\
\text { problems }\end{array}$ & .128 & $-.135-$ & $-.058-$ & .062 & $-.201-$ & $.283^{*}$ & $.780^{* *}$ & $.650^{* *}$ \\
\hline
\end{tabular}

This table indicated that there is strong positive relationship between age with duration of disease $\left(.539^{* *}\right)$ and strong negative relationship between gender with duration of disease $\left(-.660^{* *}\right)$, and strong negative relationship between residences with educational level $\left(-.569^{* *}\right)$, and then at the last that there is strong positive relationship between health problems with ( physiological $\left[.780^{* *}\right]$, and psychosocial problems $\left.\left[.650^{* *}\right]\right)$. There is no relationship between health problems with (residence [-.058 ] and educational level [.062 ] ), and there is moderate with remaining variables.

\section{Discussion}

The findings of the study samples show that the age group was (20-30) years and most of them less than 40 years old. Most of the study 


\section{Mosul Journal of Nursing, Vol. 7, No. 1, 2019 ( 44-52 )}

samples $(71.7 \%)$ were female. Most of them $(60 \%)$ were married and $(78.3 \%)$ living in rural area and (36.7\%) were secondary school graduate. The majority of the study samples $(60 \%)$ were employed and $(50 \%)$ have barely sufficient monthly income. Most of the study sample $(40 \%)$ were suffering from the disease for period (1-2) years (Table 1).

The study samples are agree with other study who reported that the majority of age group from (20-39) year. Hence females and individuals of 10-49 years of age were independently associated with high prevalence of goiter ${ }^{(22)}$.

American Cancer Society reported that the cancer of the thyroid is much less prevalent than other forms of cancer, with one fourth of the cases occurring in men and three fourths in women ${ }^{(21)}$.

The prevalence of goiter was higher in females than males in different studies in the world. Low dietary supply of iodine in areas where the soil has low iodine content is the main factor for development of Goiter ${ }^{(23)}$.

Regarding gender are agree with the prevalence of goiter was higher in girls $(56.1 \%)$ than in boys ${ }^{(24)}$.

Some of authors revealed that in Ethiopia $78.9 \%$ from the study sample were rural area ${ }^{(25)}$.

Total of 286 goiter patients were recruited. The mean age was 38 years (SD 9), 262(92\%) were females (F: M ratio 11:1), and 257(90\%) were rural- peasants. Iodine deficiency is highly prevalent among rural South Sudan communities and a likely cause for goiters. Rural poor women are highly vulnerable ${ }^{(26)}$.

The findings of the study samples show that the mean of score are high on items (Palpitation, Dyspnea, Weakness, and Hand sweat) and low on items (Exophthalmoses, and Hyperhydrosis). The mean of score are moderate on the remaining items (Table 2).

Another studies indicated that iodine deficiency is found to severely impair the physical and mental development of children. The previous studies noted that iodine-deficient children perform poorly in school, suffered from the higher incidence of learning disabilities and lower intelligent quotient (IQ) ${ }^{(19)}$. Besides to this, iodine deficiency negatively affects working capacity, quality of life and economic productivity of the community at large ${ }^{(27)}$.

When a goiter becomes very large, it can sometimes cause symptoms because it presses on adjacent structures such as the esophagus and trachea. Health problems that can occur related to a large goiter include problems with swallowing, shortness of breath, hoarseness, and stridor (a wheezing sound that results from turbulent air flow in and out of the trachea). Hashimoto's thyroiditis, a common autoimmune condition in which the body's immune response is directed against the thyroid gland, leading to inflammation of the thyroid ${ }^{(1)}$.

Health problems associated with substernal goiter may include dyspnea, dysphagia, hyperthyroidism, hoarseness, the sensation of a mass in the throat, superior vena cava syndrome, chylothorax due to thoracic duct compression, or no symptoms at all ${ }^{(28)}$.

Moreover, fatigue, poorer weight gain, cold intolerance, constipation, cretinism, congenital anomalies and iodine-induced hyperthyroidism is reported among iodine-deficient children ${ }^{(19)}$.

The prevalence of goiter is higher in Dabat District, which confirmed a moderate public health problem. Therefore, regular monitoring of household salt iodine content, improving access to safe water, promoting the importance of diversified food for children is recommended to address the higher burden of iodine deficiency (25).

The results of the study sample shows that the mean of score are high on items ( Decrease self esteem, Change in body image, Change in eating patterns, and Nervousness) and low on item ( Change in sexual function).The mean of score are moderate on the remaining items. Table 3

The result agree with this study who stated that the goiter remains as public health problem among adult population in rural Belgaum district $^{(22)}$.

Some study indicated that psychosocial problems from goiter are tiredness, forgetfulness, and mood or behavior problems, difficulties with school performance, depressed mood, and trouble concentrating ${ }^{(29)}$.

Another study reported that (nervousness, palpitations, hyperactivity increased sweating, 


\section{Mosul Journal of Nursing, Vol. 7, No. 1, 2019 ( 44-52 )}

heat hypersensitivity, fatigue, increased appetite, hair loss, weight change, forgetfulness, personality changes ${ }^{(18)}$.

Whatever your type of thyroid disorder, it can make you feel more emotional than you felt before and you may find that your mood changes, sometimes rapidly and unpredictably. Common emotional problems are: Anxiety - a feeling of nervousness, with butterflies, heart racing, trembling, irritability, sleep difficulties and Depression - low mood and difficulty enjoying things, tearfulness, loss of appetite and disturbed sleep, Mood swings - snappiness or short-temper which people often call 'moodiness' (30).

All respondents presented with a neck swelling, followed by anxiety $4(2 \%)$, palpitations and profuse sweating each at 3 $(1.0 \%)$. Voice change was seen in one respondent $(0.3 \%)^{(26)}$.

The findings of study sample indicated that there is strong positive relationship between age with duration of disease $\left(.539^{* * *}\right)$ and strong negative relationship between gender with duration of disease $\left(-.660^{* * *}\right)$, and strong negative relationship between residences with educational level $\left(-.569^{* *}\right)$, and then at the last that there is strong positive relationship between health problems with ( physiological $\left[.780^{* *}\right]$, and psychosocial problems $\left.\left[.650^{* *}\right]\right)$. There is no relationship between health problems with (residence [-.058 ]and educational level [.062 ]), and there is moderate with remaining variables ( Table 4).

\section{References}

1- American Thyroid Association. 2018 What is a goiter? Goiter Differential Diagnosis. MedscapeReference.com.

2- World Health Organization. (2007). Reducing salt intake in populations. Report of a WHO Forum and Technical Meeting 5-7 October 2006, Paris, France.Geneva, Switzerland.

3- Andersson M, Takkouche B, Egli I, Allen HE, Benoist B. Current global iodine status and progress over the last decade towards the elimination of
The authors in Turkey noted that the prevalence of goiter was negatively correlated with education level and positively correlated with body mass index (BMI) and positive family history. According to occupation, goiter prevalence was highest in farmers $(35.3 \%)$ and housewives $(32.2 \%)$. Despite a normal range of current urinary iodine excretion levels, prevalence of goiter in this adult population in a formerly iodine-deficient province of Turkey remained high, even about 10 years after salt iodine supplementation program introduction. In addition, the goiter prevalence was higher for female gender, advanced age, positive family history of goiter, low education level, and high BMI $^{(31)}$.

Other authors in Ethiopia reported that the prevalence of goiter was relatively high and therefore constituted a public health problem in this region and also the prevalence of palpable and visible goiter was significantly high among females $(21.8 \%)$ when compared to that of males $(7.2 \%)(\chi 2=15, P<0.001)$. Multiple logistic regression analysis revealed that adjusted odds ratio was significantly high for the age group ranging from 10 to 49 years ${ }^{(25)}$.

Whereas the difference in prevalence of goiter among females in these two age groups failed to show statistical significance $(\mathrm{P}=$ $0.9419)$ and when computed as a whole, no statistically significant difference $(\mathrm{P}=0.06823)$ between these two age groups for goiter prevalence was found ${ }^{32}$.

iodine deficiency. Bull World Health Organ. 2005;83(7): PP.518-25.

4- Pandav CS, Yadav K, Srivastava R, Pandav R, Karmarkar MG. Iodine deficiency disorders (IDD) control in India. Indian J Med Res 2013;138 : PP.418-33.

5- http://www.ftp://ftp.fao.org/docrep/fa o/009/a0442e/ a0442e00.pdf. [Last accessed on 2016 Jan 10].

6- Muirhead S. Diagnostic approach to goitre in children. Paediatr Child Health, 2001;6: PP.195-9.

7- Pandor JM, Damor JR, Padhiyar NG, Ninama GL. A study to measure 


\section{Mosul Journal of Nursing, Vol. 7, No. 1, 2019 ( 44-52 )}

prevalence of goiter in school children of Narmada

district, Gujarat. Natl J Community

Med, 2011;2: PP.201-3.

8- Zimmermann MBJP, Pandav CS: Iodine-deficiency disorders. Lancet 2008, 372(4): PP.1251-1262.

9- World Health Organization: WHO Global Database on Iodine Deficiency: Department of Nutrition for Health and Development. Geneva: 2004.

10-Buxton C, Baguune B. Knowledge and practices of people in Bia District, Ghana, with regard to iodine deficiency disorders and intake of iodized salt. Arch Public Health. 2012;70(5): P.5.

11-Andersson M, Zimmermann M. Global iodine nutrition: a emarkable leap forward in the past decade. IDD Newsletter. 2012;40(1): PP.1-5.

12-Adish A, Chuko T, Abay A, Assey V, Desta T. Ethiopia breaking through with new iodized salt. MI/UNICEFthiopia/GAIN/ICCIDD iodine network/FoH, Ethiopia. In. 2013.

13-Health Information. 2014. www.who.int/healthinfo/globalburden-disease/ GlobalHealthrisksreport-part2.pdf.

14-Gaffar AM, Mahfouz MS: Peace impact on health: population access to iodized salt in south Sudan in postconflict period. Croat Med J 2005, 52(2): PP.178-182.

15-Bimenya GS, Olico O, Dentos K, Mbona N, Byarugaba W: Monitoring the severity of iodine deficiency disorders in Uganda. Afr Health Sci 2002, 2: PP.63-68.

16-M. Andersson, B. Takkouche, I. Egli, H.E. Allen, B. de Benoist, Current global iodine status and progress over the last decade towards the elimination of iodine deficiency. Bull. World Health Organ, 2005, 83(7), 518-525
17-Lazarus JH. Iodine status in Europe in 2014， Eur Thyroid J, 2014;3: PP.36.

18-Healthline Media UK Ltd, Brighton, UK. (C) 2004-2018

19-WHO. Guideline: fortification of food-grade salt with iodine for the prevention and control of iodine deficiency disorders. In. Geneva: World Health Organization; 2014.

20-Emder, J., \& Jack, M: Iodine-induced neonatal hypothyroidism secondary to maternal seaweed consumption: A common practice in some Asian cultures to promote breast milk supply. Journal of Paediatric and Child Health, 2011, 47, PP.750-752.

21-Smeltzer, S.; Bare, B.; Hinkle, J.; and Cheever, K.: Textbook of Medical Surgical Nursing, $12^{\text {th }}$ ed., Lippincott Williams \& Wilkins, Philadelphia, USA, 2010, PP. 1269-1275.

22- Rao, R., Das2, A., and Kamath, G: Prevalence of Goiter in Rural Area of Belgaum District, Karnataka, Indian Journal of Community Medicine, 2009, Vol. 34, Issue 1, PP.48-51.

23-Singh MB, Marwal R, Lakshminarayan $\mathrm{J}$ : Assessment of iodine deficiency disorders in school Age children in Jodhpur dictrict of Rajasthan. J Hum Ecol, 2010, 32(2): PP.79-83.

24-Cherinet A, Kelbessa U. Determinants of iodine deficiency in school children in different regions of Ethiopia. East Afr Med J 2000;77: PP.133-7.

25-Zegeye Abebe1, Ejigu Gebeye2 and Amare Tariku: Poor dietary diversity, wealth status and use of un-iodized salt are associated with goiter among school children: a cross-sectional study in Ethiopia, BMC Public Health, 2017, 17:44, PP.5-11.

26- Chuot, C., Galukande, M., Ibingira, M., Kisa, N., and Fualal, J.: Iodine deficiency among goiter patients in 
Mosul Journal of Nursing, Vol. 7, No. 1, 2019 ( 44-52 )

rural South Sudan, BMC Research Notes, 2014, 7:751, PP.2-6.

27-Win, AZ.: Micronutrient deficiencies in early childhood can lower a country's GDP: The Myanmar example, Nutrition, 2016; 32(1): PP.138-40.

28-Hajhosseini B, Montazeri V, Hajhosseini L,: Mediastinal goiter: a comprehensive study of 60 consecutive cases with special emphasis on identifying predictors of malignancy and sternotomy. Am J Surg 2012; 203: PP.442-7.

29- Copyright (C) 2005 - 2018 Healthline Media.
30-(C) $2015 \quad$ British Thyroid Foundation.

31-Kocak, M., Erem, C., Deger, O., Topbas, M.: Current prevalence of goiter determined by ultrasonography and associated risk factors in a formerly iodine-deficient area of Turkey, Endocrine (2014) 47: PP. 290-298

32-Gupta, R., Langer, B., Raina, S., Kumari, R.: Goiter prevalence in school-going children: A cross-sectional study in two border districts of sub-Himalayan Jammu and Kashmir, Journal of Family Medicine and Primary Care, 2016, Vol.5: Issue 4, PP. 825-828. 